\title{
The Relationship between Test Takers' Critical Thinking Ability and their Performance on the Reading Section of TOEFL
}

\author{
Mansoor Fahim \\ Allameh Tabataba'i University, Tehran, Iran \\ Email: drfahim@yahoo.com \\ Marzieh Bagherkazemi \\ Allameh Tabataba'i University, Tehran, Iran \\ Email: m_b43@yahoo.com \\ Minoo Alemi \\ Sharif University of Technology, Tehran, Iran \\ Email: alemi@sharif.ir
}

\begin{abstract}
The vitality of the ability to think critically is now widely recognized among educators and assessors. Critical thinking is defined as the ability to discipline thinking through efficient information processing (Paul, 1990; cited in Longman, Atkinson \& Breeden, 1997). This study aimed at uncovering the extent to which the reading section of a ubiquitous standardized test of English language proficiency, namely TOEFL, engages the critical thinking ability of test takers. To this end, 83 advanced EFL learners completed the Watson-Glaser Critical Thinking Appraisal (1980), and the results were correlated with their scores on the reading section of Paper-Based TOEFL (PBT). The findings indicated a statistically significant advantage for those with greater critical thinking skills. Implications relate to the need to incorporate critical reading strategy training in PBT reading preparatory courses and other EFL reading programs. This way, the quality of Measurement-driven Reading Instruction and other EFL reading courses can be improved with a broader goal in mind, that of enhancing critical thinking among learners. Moreover, some of the objections lodged against the idea of teaching to the test, as the prevailing practice today, would be, to some extent, met.
\end{abstract}

Index Terms - critical thinking, standardized test, English reading proficiency, critical reading, measurement-driven instruction

\section{INTRODUCTION}

To every complex question there is a simple answer and it is wrong... (H.L. Mencken)

Critical thinking can be defined as "the systematic evaluation or formulation of beliefs, or statements by rational standards" (Vaughn, 2008). Given the extortionate rate at which massive amounts of information, arguments and counter-arguments, beliefs and interpretations are put forth, the development and exploitation of such rational standards seems to be the only path to achieving a hard core around which to shape one's own thinking and reasoning. As such, critical thinking is an ability essential for successful performance in not only educational but also professional and social contexts. The common thread running through the related literature is that it is upon educators and educational systems to develop and hone critical thinking skills in students and prepare them to look upon the realities of the world through a critical lens. This entails helping students move away from knowledge absorption to judging and evaluating information, and arguing with cogent reasons. (Ku, 2009; Kuhn, 2005; Schafersman, 1991).

Assessment, as an indispensible part of education, in general and language assessment in particular, can be designed in such a way as to best represent what a critical thinking-oriented pedagogy is supposed to achieve. The need surfaces even more visibly when one considers the stakes involved in large-scale standardized language testing. Every year, an astrological number of candidates enroll on preparatory courses for TOEFL, IELTS and other English language proficiency tests for vocational, academic and other high-stakes purposes. Therefore, in an attempt to uncover the extent to which the reading section of the Paper-Based TOEFL engages the critical thinking ability of test takers, the following question and null hypothesis were put forth:

Research question: Is there a significant relationship between test takers' critical thinking ability and their performance on the reading section of TOEFL?

Null hypothesis: There is no significant relationship between test takers' critical thinking ability and their performance on the reading section of TOEFL. 


\section{CRITICAL THINKING}

\section{A. Definition}

With the surge of the Information Era, the concept of critical thinking has received ample attention from researchers in general, simple transmission and absorption of such constantly burgeoning information being no longer possible. According to Paul, critical thinking is "learning how to ask and answer questions of analysis, synthesis and evaluation" (1985, p.37). These processes are cognitively much more demanding than those that the majority of educational systems have unconsciously valued and held in high respect, namely memorization and uncritical knowledge absorption.

In the context of language teaching, Dubin and Olshtain (1986) present a scale for assessing the cognitive potential of language learning processes drawn upon in the classroom as follows, beginning with the most through to the least cognitively demanding; of course, these processes are not exclusive to language learning and can be applied to all kinds of learning:

1. Evaluation

2. Synthesis

3. Analysis

4. Application

5. Interpretation

6. Translation

7. Memory

What Paul deems as central to the concept of critical thinking are those that Dubin and Olshtain view as the most cognitively demanding. Accordingly, developing the ability to think critically is on a par with directly engaging one's cognitive resources.

Brookfield (1987, p. 229) takes a similar path when he states that critical thinking involves two inextricably interrelated processes: "identifying and challenging assumptions, and imagining and exploring others." This definition highlights the significance of original and creative thinking in an attempt to unearth hidden agendas and judge them on the basis of one's own designated standards.

In like manner, Pithers and Soden (2000) believe underlying critical thinking are a number of abilities including:

Uncovering assumptions underlying a problem;

Focusing the problem;

Inferencing;

Inductive and deductive reasoning;

Judging the validity and reliability of assumptions and sources of information;

Notwithstanding the cognitive aspect of critical thinking, $\mathrm{Ku}$ (2009) posits an additional dispositional aspect to it, and maintains that the ability to think critically will not ensue unless one has a strong intention and initiative to engage in the processes germane to it. Simply put, "besides the ability to engage in cognitive skills, a critical thinker must also have a strong intention to recognize the importance of good thinking and have the initiative to seek better judgment." (p. 71). What $\mathrm{Ku}$ is advocating is that before trying to enhance critical thinking in learners, they must be made aware of its significance in order for the effort to yield the most satisfactory results.

\section{B. Critical Thinking and L2}

Following the recognition of the centrality of critical thinking in general education, foreign and second language learners, teachers, and researchers are now increasingly coming to grasp the concept and sketch its application in language learning and teaching. For one, Birjandi and Bagherkazemi (2010) found out a high positive correlation between Iranian EFL teachers' critical thinking ability and their student-evaluated professional success. They state that the general trend toward communicative language teaching with its emphasis on the process rather than the product of learning well embodies a greater concern with critical thinking, and believe in order to develop in learners the ability to think critically teachers themselves must possess this dispositional and cognitive capacity.

But the question is: Is critical thinking teachable in an L2 classroom? Atkinson (1997) has his doubts, offering four reasons:

1. Critical thinking is a kind of social practice, with no easily definable pedagogical set of behaviors;

2. Critical thinking is exclusive and reductive in nature.

3. Critical thinking may not be valued by some non-native cultures.

4. Critical thinking skills are not transferrable beyond their context of instruction.

Davidson (1998) takes a critical stance against Atkinson, using Siegel's (1989) terminology, "self-reflective justificatory strategy", meaning that even to make a case against critical thinking, one has to presuppose its validity, i.e. to be a critical thinker. Insofar as the cultural bias of critical thinking is concerned, he maintains:

Part of the English teacher's task is to prepare learners to interact with native speakers who value explicit comment, intelligent criticism, and intellectual assertion. Maybe even more than the L1teacher, we as L2 teachers have good reason to introduce higher level students to aspects of critical thinking. If we do not, our students may well flounder when they are confronted with necessity of thinking critically, especially in an academic setting. (p.121)

There are some studies which confirm that critical thinking is teachable in a language learning environment. For one, 
$\mathrm{n}$ a pilot study using a critical thinking essay test, a treatment group of Japanese college students receiving supplemental instruction in critical thinking skills significantly outperformed a control group receiving only content-based, intensive academic English instruction (Davidson \& Dunham, 1997).

Birjandi and Bagherkazemi (2010, p. 138) warn us against the confusion of critical thinking in TESOL with a critical approach to TESOL; they quote Pennycook (1999) as saying the former is apolitical while the latter is political in nature.

Oster (1989) points out the significance of critical thinking in American and European universities and believes a language pedagogy should help learners develop this ability. What about widespread proficiency tests, such as TOEFL and IELTS, which function as gate keepers to such universities? Should they be such designed as to test, in addition to test takers' language proficiency, their ability to think critically? Would such an ability make up part of the construct-relevant or irrelevant variance? To the researchers' best knowledge, such questions have not been approached by L2 researchers yet. In an attempt to initiate research on such issues, the present study was undertaken to determine to what extent successful performance on the reading section of the paper-based TOEFL, PBT, is contingent upon test takers' critical thinking ability.

\section{Critical Thinking and Second Language Reading}

Reading is probably the most important skill for second language learners in academic contexts. Accordingly, there is no surprise that countless number of studies have addressed this skill both theory-wise and practice-wise. Toward the end of the twentieth century, ESL reading researchers came to appreciate the psycholinguistic processes underlying reading comprehension. Sheorey and Mokhtari (2001) assert "reading is not a linear process but one in which readers constantly form hypotheses, test predictions, and use their knowledge of the world and of the language to construct meaning" (p.432). This line of research along with burgeoning evidence as to the vitality of strategic awareness and monitoring as two of the vital aspects of skilled reading (ibid) allude to the significance of reading critically if one considers the attributes of a critical thinker. There are seven key aspects of critical reading (www.criticalthinking.com):

1. Identifying the line of reasoning, an angle or point of view, a position that is being defended or a case that is being made;

2. Critically evaluating the line of reasoning in terms of relevant and contributing propositions, logical progression, false premises and flawed reasoning;

3. Questioning surface appearances and checking for hidden assumptions or agendas;

4. Identifying evidence in the text;

5. Evaluating the evidence in terms of valid criteria;

6. Identifying the writer's conclusions;

7. Deciding whether the provided evidence supports the conclusions.

\section{METhodOLOGY}

\section{A. Participants}

To answer the research question, 83 female Advanced EFL learners, ranging in age from 24 to 39, from a variety of academic backgrounds, learning English at a private language institute in Iran took part in the study. They had all been placed into two consecutive advanced levels ( $\mathrm{Ad} 3$, and $\mathrm{Ad} 4$ ) and homogenized on their reading comprehension proficiency by the researcher (see Procedure).

\section{B. Instruments}

For the purposes of the present study, three instruments were utilized:

1. Watson-Glaser Critical Thinking Appraisal-Form A (Watson \&Glaser, 1980)

The Watson-Glaser critical Thinking Appraisal comprises five subsections which practically measure the five aspects of critical thinking as defined by Watson and Glaser (1980):

Drawing inferences based on factual statements;

Recognition of assumptions in a number of assertive statements;

Making deductions: To determine if conclusions follow from information in given statements;

Interpreting evidence to decide if conclusions are legitimate or not;

Evaluating arguments as being strong or weak;

The appraisal consists of general scenarios along with 16 items for each aspect of the construct and is not subject-related (Watson \& Glaser, 1980). It includes 80 items each followed by two to five alternatives, which can be completed in 60 minutes. In addition to the face, content, construct, and criterion validity of the appraisal, its test-retest reliability has been shown ( $\mathrm{r}=0.81)$ by Watson and Glaser (1980). The researcher used the Farsi version of the appraisal, translated by Faravani (2006), of which the reported reliability is $85 \%$ (Cronbach's $\alpha=0.85$ ). Scoring is facilitated through the availability of an answer key, yielding a composite score for the five subsections of the appraisal from 0 to 80 .

2. The Reading Section of general training IELTS

On this reading test, there are 40 questions for the candidates to be answered within 60 minutes, following 3 sections 
of increasing difficulty containing texts taken from notices, advertisements, leaflets, newspapers, instruction manuals, books and magazines (www.IELTS.org).

Each item is worth one mark and scoring is facilitated through the availability of an answer key indicating alternative words/phrases within an individual answer (Cambridge IELTS 2, 2002). Scores on the Reading module in the present study were scaled on full and half band scores from 0 to 9.

3. The Reading Section of PBT (paper-based TOEFL)

The reading section of PBT makes up the third section of the test. It contains 50 multiple-choice questions with a completion time limit of 55 minutes. The version used in the present study comprised 5 passages each followed by 9 to 11 multiple-choice items. Generally, passages are written in a formal, academic style, typical of most college or university level texts and journals (www.TOEFL.org). The scoring was carried out by first calculating the number right scores and then converting them to scaled scores ranging from 31 to 67.

\section{Procedure}

To expedite the study, initially 117 female advanced EFL learners, placed through interviews or placement tests into two consecutive advanced levels ( $\mathrm{Ad} 3$ and $\mathrm{Ad} 4$ ), in 8 classes altogether, were selected as the participants of the study. To homogenize them on their reading comprehension ability, the eight classroom teachers administered the reading section of a 2002 version of General Training IELTS during the regular class time. Subsequently, for the purposes of the present study, those who scored below or above one standard deviation from the mean were excluded from data analysis. Out of 117 test takers, 96 scored within one standard deviation from the mean.

Having gained a homogeneous sample in terms of English reading comprehension ability, the next step was to obtain the participants' scores on the reading section of PBT, and the Critical Thinking Appraisal. The reading section of a 2002 version of PBT was administered, within one week from the first testing session, by the same classroom teachers during the regular class time. Finally, due to time limitation, the participants were asked to complete the Farsi version of the Critical Thinking Appraisal, which has a time limit of 50 minutes, in their free time. On the whole, the number of participants for the final data analysis shrank to 83 due to either absence on the second testing session or failure to make time to complete the Critical Thinking Appraisal.

\section{Data Analysis}

To answer the research question, the $16^{\text {th }}$ version of the Statistical Package for Social Sciences (SPSS) was utilized. First, to ensure the homogeneity of the sample on English reading proficiency, after calculating the mean and standard deviation of the participants' scores on the reading subsection of the General Training IELTS, only those scores which fell within one standard deviation from the mean were included in further data analysis. Totally, 83 participants met the score requirement at this stage. Table 1 contains the descriptive statistics of the test takers' performance on the reading section of IELTS, and Figure 2 provides a visual representation of the distribution of these scores.

TABLE 1:

IELTS SCORES' DESCRIPTIVE STATISTICS

\begin{tabular}{|l|l|l|l|l|l|}
\hline & $\mathrm{N}$ & Minimum & Maximum & Mean & Std. Deviation \\
\hline IELTS Scores & 117 & 2.00 & 8.50 & 4.5470 & 1.39578 \\
Valid N & 117 & & & & \\
\hline
\end{tabular}

Having obtained the scores of 83 out of the 97-member homogenized sample on the reading section of PBT and the Critical Thinking Appraisal (see Table 2), the researchers set off on the task of testing the null hypothesis:

There is no significant relationship between test takers' critical thinking ability and their performance on the reading section of TOEFL.

Statistically speaking, the assumption behind the null hypothesis is that the correlation coefficient between the participants' scores on the reading section of PBT and the WGCTA has a value of zero $(\mathrm{r}=0)$. In order to test this claim, a Pearson product-moment correlation coefficient was run. Table 3 presents the outcome of this analysis. As shown in the table, the correlation coefficient between the two variables at issue, namely performance on the reading section of paper-based TOEFL and the critical thinking ability of test takers has a value of 0.8 which is significant at 0.01 level $(\mathrm{r}=0.8, P \leq 0.01)$. This value by a wide margin exceeds zero. Therefore, the null hypothesis is rejected since the two variables are significantly positively correlated with each other. Figure 3 represents this correlation mapping PBT reading scores on WGCTA scores. 


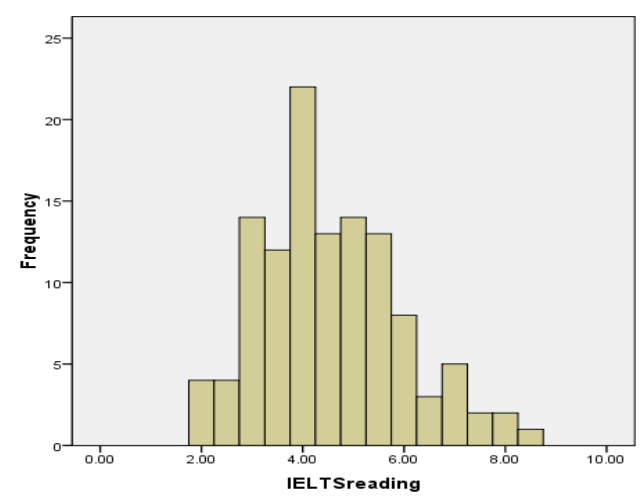

Figure 2 IELTS reading scores' distribution

TABLE2:

DESCRIPTIVE STATISTICS

\begin{tabular}{|l|l|l|l|l|l|}
\hline & Mean & Std. Deviation & Minimum & Maximum & N \\
\hline PBT reading scores & 51.4699 & 8.02790 & 40 & 65 & 83 \\
WGCTA scores & 40.3012 & 19.12203 & 8 & 71 & 83 \\
\hline
\end{tabular}

TABLE 3:

PEARSON PRODUCT MOMENT CORRELATION COEFFICIENT

\begin{tabular}{|ll|l|l|}
\hline & PBT reading scores & WGCTA scores \\
\hline PBT reading scores Pearson Correlation & 1 & $.807^{* *}$ \\
& Sig. (2-tailed) & & .000 \\
& $\mathrm{~N}$ & 83 & 83 \\
\hline WGCTA scores & Pearson Correlation & $.807^{* *}$ & 1 \\
& Sig. (2-tailed) & .000 & \\
& $\mathrm{~N}$ & 83 & 83 \\
\hline
\end{tabular}

**. Correlation is significant at the 0.01 level (2-tailed).

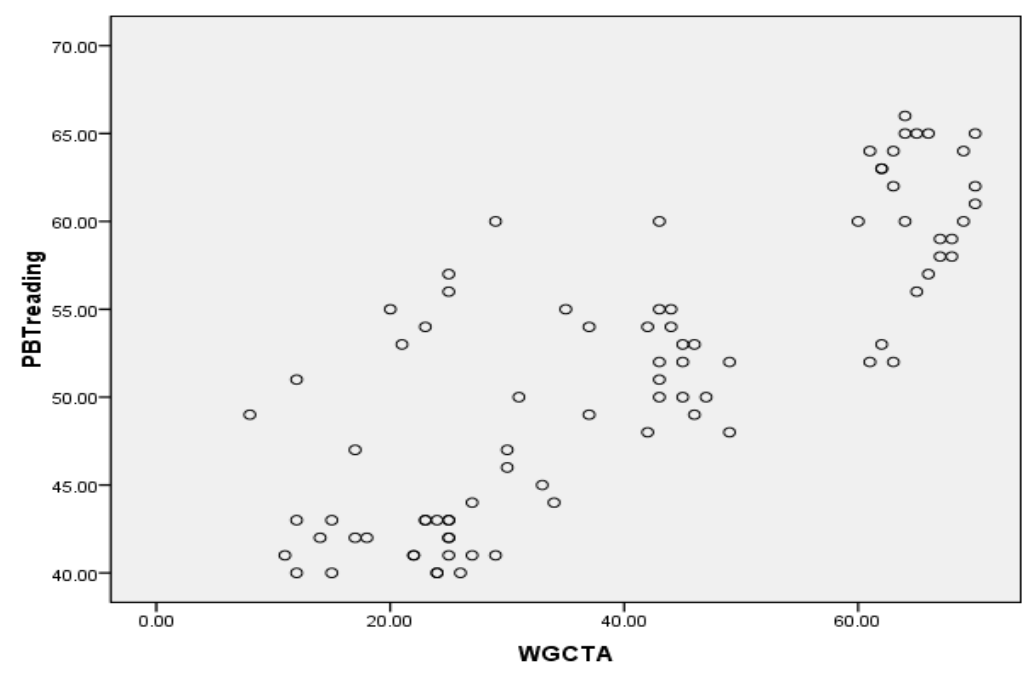

Figure 3: Scattergram of the correlation of PBT reading scores and WGCTA scores

\section{Discussion}

Paper-based TOEFL (PBT) and more recently Computer-based TOEFL (CBT) and Internet-based TOEFL (IBT) have always functioned as one of the most demanding gate keepers to a myriad of workplaces and academic institutions in the majority of English-speaking and even non-English speaking countries. Their growing significance calls for an investigation into the way such tests and their different sections are allied with cognitive notions of current interest in psychology and in language pedagogy. One such notion is the ability to think critically. The present study substantiated a significant positive correlation between performance on the reading section of PBT and the ability to think critically. With the five components of critical thinking as defined by Watson and Glaser (1980), the observed outcome of the 
statistical analysis would have been expected.

Generally, there are three types of question in the reading section of PBT: vocabulary, cohesion, and reading comprehension items including factual questions and questions about the main idea of individual paragraphs and the whole passage (Matthiesen, 1999). The ability to answer all these three item types can be in some way linked to the ability to think critically. Meanings of the vocabulary items and cohesive links are heavily contingent upon the context in which they occur and working them out is a cognitively demanding task. Critical thinking seems to be even more significant for answering reading comprehension questions, especially those related to main ideas.

Having substantiated a close link between critical thinking and performance on the reading section of PBT does not, however, imply a cause-effect relationship between the two variables, and heed needs to be taken not to get trapped in the ever present threat to correlational studies, namely post hoc fallacy. For sure, performance on the subtest at issue is influenced by multitudinous other factors which have been investigated or are in need of investigation.

\section{CONCLUSION}

The present study was carried out to find out if there was a statistically significant correlation between the critical thinking ability of test takers and their performance on the reading section of PBT (paper-based TOEFL). The relatively high positive correlation observed between the two variables at issue has some important implications as far as English reading instruction is concerned. First and foremost, it invokes upon L2 reading instructors to try to develop in learners the ability to read critically if they are to enhance the efficiency of their courses. This can border on critical reading strategy training. There are a lot of critical reading strategies which are applicable to all kinds of reading. What follows is a sketch of some of these strategies (www.alamo.edu):

1. Annotating:

a. Underlining key words, phrases and sentences;

b. Writing comments or question in the margins;

c. Bracketing important sections of the text;

e. Constructing ideas with lines or arrows;

f. Numbering related points in sequence;

g. Making note of interesting, important or questionable points;

2. Previewing:

a. Going over head notes and other introductory material;

b. Skimming to get an overview of the content and its organization;

c. Identifying the rhetorical situation;

3. Contextualizing:

a. Placing a text in its historical, biographical and cultural context;

b. Recognizing differences between one's own values and attitudes and those represented in the text;

4. Questioning:

a. Asking questions about the content of the text;

b. Writing questions for different sections of a text in one's own words focusing on a main idea;

5. Reflecting on challenges to one's values and beliefs:

a. Marking challenging statements;

b. Making note of one's own feelings, attitudes and beliefs in relation to parts of a text;

6. Outlining main ideas;

7. Summarizing through creative synthesis;

8. Evaluating an argument in terms of its logic, credibility and emotional impact:

a. Recognizing every assertion as an argument to be evaluated;

b. Discriminating between claims and their supporting reasons and evidence;

9. Comparing and contrasting related readings

The list is by no means exhaustive. It is upon the teachers to base their use of these and other strategies which they deem as promising in enhancing their students' critical thinking ability on a an analysis of the idiosyncratic features of their teaching context.

The results of the present study also have some implications regarding MDI (Measurement-Driven Instruction) reading courses which are now widely exploited to provide learners with some handy strategies to boost their performance on high stakes language proficiency tests. Among such tests, TOEFL and IELTS stand out. The negative washback of such high stakes tests on the teaching and learning leading up to them is most evident in such strategy training. However, the results of this study can, to some extent, alleviate the situation since if teachers focus on critical reading strategies, the aim of MDI courses would be two-fold:

1. Preparing learners for the reading section of PBT;

2. Enhancing in learners the ability to think critically; 
[1] Atkinson, D. (1997). A critical approach to critical thinking in TESOL. TESOL Quarterly, 31 (1): 79-95.

[2] Birjandi, P. \& Bagherkazemi, M. (2010). The relationship between Iranian EFL teachers' critical thinking ability and their professional success. English Language Teaching, 3(2): 135-145.

[3] Birjandi, P. \& Bagherkazemi, M. (2010). The relationship between Iranian EFL teachers' critical thinking ability and their professional success. English Language Teaching, 3(2): 135-145.

[4] Brookfield, S. (1987). Developing critical thinkers. Milton Keyes: Open University Press.

[5] Cambridge IELTS 2. (2002). Cambridge: Cambridge University Press.

[6] Davidson, B.W. (1998). A case for critical thinking in the English language classroom. TESOL quarterly, 32 (1): $119-123$.

[7] Davidson, B., \& Dunham, R. (1997). Assessing EFL student progress in critical thinking with the Ennis-Weir Critical Thinking Essay Test. JALT Journal, 19: 43-57.

[8] Dubin, F. \& Oldstein, E. (1986). Course design. Cambridge: Cambridge University Press.

[9] Faravani (2006). Portfolio and critical thinking. Unpublished M.A. Thesis. Iran: Mashahd's Ferdowsi University.

[10] Ku, Y. L. K. (2009). Assessing students' critical thinking performance: Urging for measurements using multi-response format. Thinking Skills and Creativity, 4: 70-76.

[11] Kuhn, D. (2005). Education for thinking. Cambridge: Harvard University Press.

[12] Longman, D.G., Atkinson, R.H., \&Breeden, J.A. (1997). Strategic thinking and reading. Boston: Heinle \& Heinle Publishers.

[13] Matthiesen, S.J. (1999). Barron's essential words for the TOEFL (2nd ed.). USA: Barron's.

[14] Oster, J. (1989). Seeing with different eyes: Another view of literature in the ESL class. TESOL Quarterly, 23(1): 85-103.

[15] Paul, R. W. (1985). Bloom's taxonomy and critical thinking intervention. Educational Leadership, 42(8): 36-39.

[16] Pennycook, A. (1999). Introduction: Critical approaches to TESOL. TESOL Quarterly 33, 329-348.

[17] Pithers, R. T., \& Soden, R. (2000). Critical thinking in education: A review. Educational Research, 42: 237-249

[18] Schafersman. (1991). An introduction to critical thinking. Retrieved January 1, 2010 from: www.freeenquiry/criticalthinking.html

[19] Sheorey, R. \& Mokhtari, K. (2001). Differences in the metacognitive awareness of reading strategies among native and non-native readers. System, 29:431-449

[20] Siegel, H. (1988). Educating reason: Rationality, critical thinking, and education. New York: Routledge.

[21] TOEFL actual tests administered in the past by ETS. (2006). Tehran: Nashre Ebteda.

[22] Vaughn, L. (2008). The power of critical thinking: Effective reasoning about ordinary and extraordinary claims (2nd ed.). Oxford: Oxford University Press.

[23] Watson, G., \& Glaser, E. (1980). Watson-Glaser critical thinking appraisal. England: The Psychological Corporation.

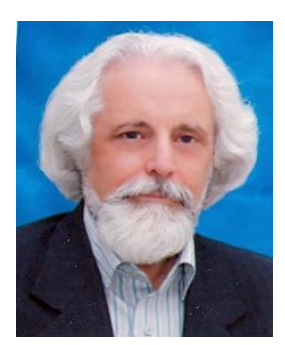

Mansoor Fahim was born in Iran in 1946. He received a Ph.D. in TEFL (Teaching English as a Foreign Language) from Islamic Azad University in Tehran, Iran in 1994, an M.A. in General Linguistics from Tehran University in Tehran, Iran in 1978, and a B.A. in English Translation from Allameh Tabataba'i University in Tehran, Iran in 1975.

As for his professional background, he was the chairman of the EFL department at Allameh Tabataba'i University from 2003 to 2007 and a member of the faculty of English Language and Literature at Allameh Tabataba'i University in Tehran, Iran from 1979 to 2008 when he was retired as an associate professor of TEFL. He has also taught English at a welter of universities and language schools. At present, he runs Psycholinguistics, Applied Linguistics, First and Second Language Acquisition, and Discourse Analysis courses at M.A. and Ph.D. levels at a number of universities in Iran, including Allameh Tabataba'i and Islamic Azad Universities. Moreover, he has several published articles and books mostly in the field of TEFL including: (1) Fahim, M. \& Nezakatgoo, B. (2006). GRE general words for graduate and post-graduate students. Tehran: Rahnama Publications. (2) Ghobadi, A. \& Fahim, M. (2009). The effect of explicit teaching of English 'thanking formulas' on Iranian EFL intermediate level students at English language institutes', System: 526-537. (3) Fahim. M., Bagherkazemi, M. \& Alemi, M. (2010). The relationship between test takers' multiple intelligences and their performance on the reading sections of TOEFL and IELTS.BRAIN. Broad Research in Artificial Intelligence and Neuroscience, 1 (3) : 27-41.

Dr. Mansoor Fahim is currently a member of the editorial board of the Iranian journal of Applied Linguistic Studies, Sistan \& Baloochestan University, Iran; Journal of Language Studies, Shahrekord University, Iran; and Journal of English Language Studies, Islamic Azad University, Tehran, Iran.

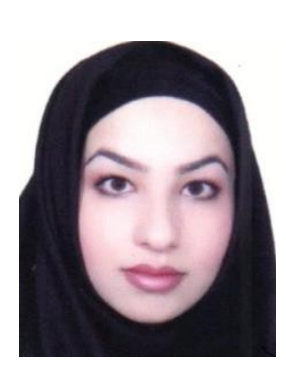

Marzieh Bagherkazemi was born in Iran in 1983. She has been a Ph.D. candidate of TEFL (Teaching English as a Foreign Language) at Allameh Tabataba'i University in Tehran, Iran since September 2009. She graduated B.A. in English literature and M.A. in TEFL both at Allameh Tabataba'i University in Tehran in 2005 and 2008 respectively.

As for her professional background, she has taught English at a number of language schools, and tutored courses in IELTS, TOEFL and FCE since 2003. She has also been a lecturer, running General English and English Grammar courses at Allameh Tabataba'i, San'ati Sharif and Islamic Azad universities in Tehran, Iran since 2008. Moreover, she has been involved in research on language learning and teaching issues, and co-authored a number of articles including: (1) Fahim. M., Bagherkazemi, M. \& Alemi, M. (2010). The relationship between test takers' multiple intelligences and their performance on the reading sections of TOEFL and IELTS.BRAIN. Broad Research in Artificial Intelligence and Neuroscience, 1 (3): 27-41. (2) Birjandi, P. \& Bagherkazemi, M. (2010). The relationship between EFL teachers' critical thinking ability and their professional success. English 
language Teaching, 3 (2): 135-145. (3) Bagherkazemi, M. \& Alemi, M. (2010). Literature in the EFL/ESL classroom: Consensus and Controversy. LiBRI. Linguistic and Literary Broad Research and Innovation, 1(1): 30-48. Her research interests include personality variables in language learning and teaching, issues in language teacher education, L2 reading, materials evaluation and oral proficiency assessment.

Ms. Bagherkazemi is currently a member of the editorial board of the Romanian journal 'LiBRI. Linguistic and Literary Broad Research and Innovation', and of the Teaching English Language and Literature Society of Iran (TELLSI).

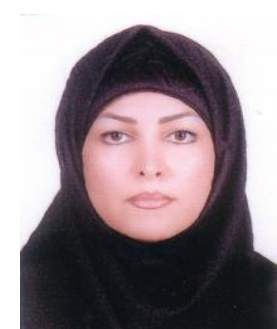

Minoo Alemi was born in Iran. She has been a Ph.D. candidate of TEFL (Teaching English as a Foreign Language) at Allameh Tabataba'i University in Tehran, Iran since September 2009. She graduated B.A. in English literature and M.A. in TEFL at Allameh University and Khatam University in Tehran.

As for her professional background, she has taught English over a decade at different universities in Iran. Moreover, she has been faculty member and vice-Dean of Education at Languages and Linguistics Department at Sharif University of Technology since 2008. Her main areas of interest are (1) second language acquisition, (2) ESP, (3) vocabulary, and (4) syllabus design. Alemi has published about ten textbooks in General English and ESP, a large number of papers in different areas in international journals, and given presentations on TEFL at many international conferences.

Ms. Alemi is a member of scientific board of LiBRI, Linguistic and Literary Broad Research and Innovation journal and JLTR, Journal of Language Teaching and Research. 